\title{
Efeitos de intervenção educativa no conhecimento de escolares sobre aleitamento materno
}

\author{
Effects of educational intervention on knowledge of schools about breastfeeding \\ Efectos de la intervención educativa sobre el conocimiento de las escuelas sobre la lactancia materna
}

\begin{abstract}
RESUMO
Objetivo: Comparar o conhecimento de escolares sobre aleitamento materno, antes e após intervenção educativa. Método: estudo comparativo, transversal, com abordagem quantitativa, realizado no período de março a outubro de 2018 em escolas públicas municipais em um município piauiense com 24 escolares de 7 a 9 anos. Nesse estudo, foi realizado um pré-teste que avaliou o conhecimento de escolares, uma intervenção educativa com uso da história em quadrinhos impressa e jogo educativo. Após intervenção, aplicou-se pós-teste seguindo-se de análise comparativa do conhecimento em relação ao aleitamento materno. Resultados: do total de entrevistados no pré-teste, 12 obtiveram conhecimento insuficiente, 3 obtiveram bom conhecimento e nenhum alcançou o conhecimento ótimo. Após a intervenção educativa, constatou-se que nenhum escolar obteve conhecimento insuficiente e 19 escolares foram classificados com conhecimento bom. Conclusão: Foi possível observar uma melhora nos níveis de conhecimento após a intervenção educativa.
\end{abstract}

DESCRITORES: Aleitamento Materno; Serviços de Saúde Escolar; Conhecimento; Criança.

\section{ABSTRACT}

Objective: To compare the knowledge of schoolchildren about breastfeeding, before and after educational intervention. Method: a comparative, cross-sectional study, with a quantitative approach, carried out from March to October 2018 in municipal public schools in a municipality in Piauí, with 24 students aged 7 to 9 years. In this study, a pre-test was carried out to assess the knowledge of schoolchildren, an educational intervention using printed comic books and an educational game. After intervention, a post-test was applied, followed by a comparative analysis of knowledge in relation to breastfeeding. Results: out of the total number of interviewees in the pre-test, 12 obtained insufficient knowledge, 3 obtained good knowledge and none achieved optimal knowledge. After the educational intervention, it was found that no student had insufficient knowledge and 19 students were classified as having good knowledge. Conclusion: It was possible to observe an improvement in the levels of knowledge after the educational intervention.

DESCRIPTORS: Breastfeeding; school health services; knowledge; child.

\section{RESUMEN}

Objetivo: Comparar los conocimientos de los escolares sobre lactancia materna, antes y después de la intervención educativa. Método: estudio comparativo, transversal, con enfoque cuantitativo, realizado de marzo a octubre de 2018 en escuelas públicas municipales de un municipio de Piauí, con 24 alumnos de 7 a 9 años. En este estudio se realizó una prueba previa para evaluar los conocimientos de los escolares, una intervención educativa mediante cómics impresos y un juego educativo. Después de la intervención, se aplicó una prueba posterior, seguida de un análisis comparativo de conocimientos en relación con la lactancia materna. Resultados: del total de entrevistados en el pre-test, 12 obtuvieron conocimientos insuficientes, 3 obtuvieron buenos conocimientos y ninguno alcanzó conocimientos óptimos. Después de la intervención educativa, se encontró que ningún alumno tenía conocimientos insuficientes y 19 alumnos fueron clasificados como de buen conocimiento. Conclusión: se pudo observar una mejora en los niveles de conocimiento luego de la intervención educativa.

DESCRIPTORES: Lactancia Materna; servicios de salud escolar; conocimiento; niño.

RECEBIDO EM: 17/08/2020 APROVADO EM: 01/09/2020 


\section{Míria Kayny da Silva Leão}

Enfermeira. Mestranda em Enfermagem do Programa de Pós-graduação em Enfermagem da Universidade Federal do Ceará/ UFC. Fortaleza (CE), Brasil.

ORCID: 0000-0001-7789-3263

\section{Maurilo de Sousa Franco}

Acadêmico de Enfermagem. Universidade Federal do Piauí/UFPI. Picos (PI), Brasil. Bolsista de Iniciação Científica Voluntário-ICV-UFPI.

ORCID: 0000-0003-0808-3763

\section{Gyzelda de Barros Sousa}

Enfermeira pela Universidade Federal do Piauí/UFPI, Picos (PI). Pós graduanda em docência do ensino superior. Docente de Cursos de nível médio-técnico no instituto Invictus - PI e Seduc- PI.

ORCID: 0000-0003-2193-2467

\section{Roseanne de Sousa Nobre}

Enfermeira. Doutoranda do Programa de Pós-graduação em Epidemiologia da Universidade de São Paulo/USP. Docente do Instituto Federal do Alagoas/IFAL, Maceió (AL).

ORCID: 0000-0002-7489-4401

\section{Hiugo Santos do Vale}

Enfermeiro. Residente em Saúde da Família pela Universidade Estadual do Maranhão/UEMA. Caxias (MA), Brasil. ORCID: 0000-0001-5282-2418

\section{Luisa Helena de Oliveira Lima}

Enfermeira. Doutora em Enfermagem pela Universidade Federal do Ceará. Atualmente é Líder do Grupo de pesquisa Inovação e Tecnologia no Ensino e no Cuidado na Saúde (ITECS) e pesquisadora do Grupo de Pesquisa Saúde Coletiva e Professora Associada da Universidade Federal do Piauí. Picos (PI), Brasil.

ORCID: 0000-0002-1890-859X

\section{INTRODUÇÃO}

ão inegáveis os benefícios que a prática da amamentação oferece a díade mãe-filho, destacando-se entre esses, a redução da morbimortalidade infantil, fortalecimento de vínculo, além de ser um alimento ecológico e ajudar dessa forma a sociedade a ser mais sã e sustentável ${ }^{(1)}$. Contudo, embora encontram-se evidências comprovadas acerca desses benefícios, a literatura aponta que em países de baixa e média renda as prevalências dessa prática são abaixo de $37 \%$ em menores de seis meses ${ }^{(2)}$.

No panorama nacional, apenas 9,3\% das crianças são amamentadas exclusivamente ${ }^{(3)}$, o que sugere a necessidade de pensar em intervenções educativas para melhora desse quadro em fases iniciais $\mathrm{da}$ vida, como a fase escolar, além de intervir em diversos cenários, a exemplo da família e o ambiente escolar ${ }^{(4)}$.

Hodiernamente, há a prevalência de intervenções planejadas e executadas no ciclo gravídico-puerperal, podendo ser um momento limitante para adoção de uma postura/atitude futura frente à prática do aleitamento materno, pois quanto mais cedo a população é informada sobre a importância do aleitamento materno maiores serão as chances de decisões positivas sobre esse ato ${ }^{(5-17)}$. Nota-se, então, que é incipiente o planejamento e consolidação de estratégias educacionais que possam promover o conhecimento e cultura o aleitamento materno direcionadas a crianças escolares.

Estudos de intervenção utilizando tecnologias educacionais ${ }^{(4)}$ têm se mostrado eficazes para promover o conhecimento de estudantes escolares sobre aleitamento materno, a exemplo disso um estudo realizado no Recife (PE), com crianças do ensino fundamental utilizando uma tecnologia educacional do tipo jogo de tabuleiro, apresentou efeito positivo ao comparar o conhecimento sobre aleita- mento materno entre o grupo intervenção e o grupo controle.

Nesse cenário, sobretudo quando analisamos as ações de promoção e de intervenções educacionais que desfechem positivamente na disseminação do conhecimento e prática do aleitamento, novos recursos vêm sendo utilizados, dentre eles destacam-se o uso de tecnologias educativas como um instrumento capaz de viabilizar o conhecimento e despertar o interesse pela temática. Dessa forma, materiais como histórias em quadrinhos educacionais, são importantes veículos de informação na promoção de saúde além de eficientes nesse processo, estimulam a reflexão nos indivíduos, criando a oportunidade para que o receptor transforme sua realidade ou a do meio em que está inserido ${ }^{(6)}$.

Desse modo, fomentar o diálogo sobre amamentação em outras fases, ainda que iniciais no seio familiar e na escola ${ }^{(7)}$, pode propiciar a adesão de conhecimentos posi- 
tivos à saúde e contribuir para a diminuição de fatores que interferem na duração e na manutenção do Aleitamento Materno de forma positiva.

Não obstante, para que se compreenda os reais benefícios alcançados através do uso de um instrumento educacional, faz-se necessário comparar o conhecimento prévio e o conhecimento após a intervenção. Portanto, este estudo emergiu do seguinte questionamento: qual o nível de conhecimento dos escolares sobre aleitamento materno, após a aplicação de uma tecnologia educativa?

Dessa forma, este estudo objetivou comparar o conhecimento de escolares sobre aleitamento materno, antes e após intervenção educativa.

\section{MÉTODO}

Trata-se de um estudo comparativo, com abordagem quantitativa, realizado em duas escolas da rede municipal de uma cidade no centro-sul piauiense. Foram convidadas para participarem do estudo as escolas públicas de ensino fundamental com maior quantitativo de alunos matriculados.

A coleta de dados ocorreu no período de março a outubro de 2018. Foram incluídos todos os estudantes entre 7 a 9 anos de idade. O cálculo amostral para comparação de subgrupos dentro de uma amostra depende do teste estatístico escolhido, das diferenças entre os grupos, da tolerância do pesquisador à detecção de diferenças quando elas não existem (erro tipo I) ou da falha na detecção de diferenças entre os subgrupos quando elas realmente existem (erro tipo II). As probabilidades associadas aos erros tipos I e II são convencionadas como $\alpha$ e $\beta$, e comumente, são adotados valores de $5 \%$ (bilateralmente) e $20 \%$, mas outros valores podem ser utilizados de forma criteriosa. Dessa forma através do cálculo amostral foram incluídas 24 crianças no estudo, das quais foram selecionadas através de sorteio aleatório utilizando o aplicativo Random Selection Generator ${ }^{\circ}$, em todas as turmas com pelo menos um aluno dentro da faixa etária.
Este estudo foi realizado a partir dos resultados de duas pesquisas: 1 . Onde avaliou-se o conhecimento de escolares de 7 a 9 anos por meio da aplicação de um questionário contendo perguntas abertas e de múltipla escolha, relacionadas à dados socioeconômicos e conhecimento sobre amamentação ${ }^{(8)}$. 2. Construção e validação de material educativo denominado "História em quadrinhos: Aprendendo sobre Aleitamento Materno". A investigação do conhecimento dos escolares se deu a partir da comparação do conhecimento antes e depois da aplicação da história em quadrinho ${ }^{(9)}$.

A revista em quadrinho discorre sobre o que significa AM para os mamíferos e a importância do leite da mãe para o crescimento e desenvolvimento do bebê e demais benefícios, o uso inadequado de chupetas e mamadeira, e amamentação cruzada. Além disso, foram abordados mitos sobre a amamentação e a importância fundamental da presença do pai ou companheiro durante o $\mathrm{AM}^{(9)}$.

Os escolares foram divididos em quatro grupos com 6 participantes em cada um. Cada grupo participou de dois encontros quinzenais com a equipe da pesquisa. No primeiro encontro foi realizada a leitura e discussão do conteúdo da história em quadrinhos. No segundo encontro, foi desenvolvido um jogo educativo criado pela pesquisadora e intitulado por "amarelinha”. Neste, os participantes, com uso de um dado confeccionado pela equipe da pesquisa, arremessavam-no na amarelinha. Os números da amarelinha correspondiam a uma pergunta ou uma nova chance de arremesso ou passe a frente ou retorne a casa anterior. Se a pergunta fosse respondida corretamente o candidato permanecia na casa numérica. Aquele que primeiro que chegou ao final do jogo era o ganhador.

Por fim, o formulário de pós-teste foi aplicado para análise posterior do conhecimento dos escolares sobre AM, individualmente, com todos os escolares dos grupos de intervenção. A aplicação do questionário foi realizada em sala reservada, confortável e livre de interferências.

Os dados foram analisados com base na literatura específica e em tratamento estatístico, utilizando o programa Microsoft Office Excel $2007^{\circ}$ e posteriormente exportados para software Statistical Package for the Social Scienc (SPSS) versão 20.0 para Windows.

O nível de conhecimento dos escolares sobre o AM foi classificado de acordo com as seguintes opções: ótimo, bom, regular e insuficiente. Considerando os resultados obtidos, o conhecimento dos escolares foi classificado em ótimo quando atingia > $76 \%$ de acertos; bom quando o resultado atingia entre 51 a $75 \%$ de acertos; regular, entre 26 a 50\% de acertos; e insuficiente $<25 \%$ de acertos ${ }^{(10)}$. Foi utilizado o teste $\mathrm{T}$ de student para amostras pareadas, a significância adotada foi de $\mathrm{p}<0,005$.

Para a realização desta pesquisa foram respeitados todos os princípios éticos contidos na Resolução 466/12 (11) que rege pesquisas envolvendo seres humanos. Assim os escolares que, aos que concordaram participar da pesquisa, foi assinado um Termo de Consentimento Livre e Esclarecido (TCLE), pelos seus respectivos pais ou responsáveis, além de um Termo de Assentimento Livre e Esclarecido (TALE) assinado pelos sujeitos da pesquisa.O projeto foi aprovado pelo Comitê de Ética e Pesquisa da Universidade Federal do Piauí do Campus Senador Helvídio Nunes de Barros, sob o $\mathrm{n}^{\circ} 1.840 .137$ e CAAE 59687916.7.0000.8057

\section{RESULTADOS}

Apresentam-se a seguir os resultados referentes aos dados sociodemográficos e o conhecimento antes da intervenção educativa dos escolares sobre aleitamento materno.

Dentre os escolares pesquisados, constatou-se que maior parte dos estudantes têm 8 anos de idade (58,3\%), estão matriculados no segundo ano do ensino fundamental $(62,5 \%)$, referem cor parda (50\%), moram na zona urbana da cidade $(91,7 \%)$ e possuem renda familiar menor ou igual a um salário mínimo (41,7\%). Além disso, dentre os estudantes, houve maior participação do sexo feminino $(70,8 \%)$. 


\section{artigo}

Leão, M.K.S.; Franco, M.S.; Sousa, G.B.; Nobre, R.S.; Vale, H.S.; Lima, L.H.O.

Efeitos de intervenção educativa no conhecimento de escolares sobre aleitamento materno

Tabela 1. Conhecimento antes da intervenção dos escolares sobre aleitamento materno. Picos- Pl, 2018 ( $n=24)$.

\section{VARIÁVEIS}

Sabe até quando o bebê deve mamar só no peito.

Sabe até quando o bebê deve mamar no peito.

Sabe quando o bebê deve receber outros alimentos dife-rentes do leite do peito.

Acha que o bebê que mama só no peito deve tomar água.

Acha que o bebê que mama só no peito deve tomar chá.

Acha que o bebê que mama só no peito deve tomar suco.

Qual (ais) a(s) vantagens do aleitamento materno.

Acha correto dar outro tipo de leite que não o materno pa-ra o bebê.

Acha correto o uso de mamadeiras e chupetas por bebês.

Fonte: dados da pesquisa.

Tabela 2. Conhecimento pós-intervenção dos escolares sobre aleitamento

materno. Picos-PI, 2018. ( $n=24)$.

$$
\text { VARIÁVEIS }
$$

Sabe até quando o bebê deve mamar só no peito.

Sabe até quando o bebê deve mamar no peito.

Sabe quando o bebê deve receber outros alimentos dife-rentes do leite do peito.

Acha que o bebê que mama só no peito deve tomar água.

Acha que o bebê que mama só no peito deve tomar chá.

Acha que o bebê que mama só no peito deve tomar suco.

Qual (ais) a(s) vantagens do aleitamento materno.

Acha correto dar outro tipo de leite que não o materno

pa-ra o bebê.

Acha correto o uso de mamadeiras e chupetas por bebês.

Fonte: dados da pesquisa.

Gráfico 1. Conhecimento pré e pós intervenção.

\section{CONHECIMENTO}

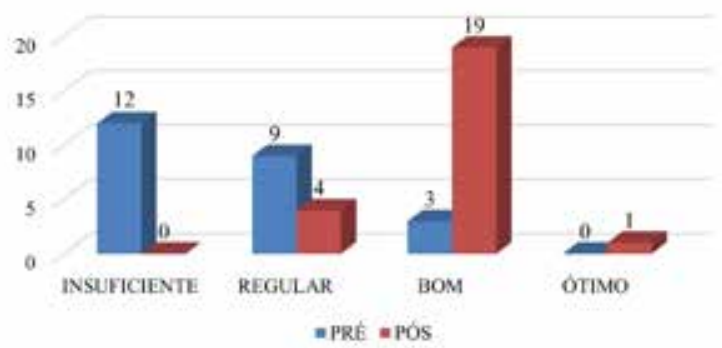

O conhecimento dos escolares após a intervenção educativa mostrou-se bastante significativo em relação ao anterior. Antes da intervenção, evidenciou-se que do total de entrevistados ( $n=24), 12 \mathrm{ob}$ tiveram conhecimento insuficiente, 3 obtiveram bom conhecimento e nenhum alcançou o conhecimento ótimo. Após a intervenção educativa constatou-se que nenhum escolar obteve conhecimento insuficiente e 19 escolares foram classificados com conhecimento bom (Gráfico 1).

As médias das notas das crianças antes e depois da intervenção foram 10,42 e 64,58 , respectivamente. De acordo com o teste $\mathrm{T}$ para amostras pareadas, houve diferença de médias antes e após a intervenção educativa $(\mathrm{p}<0,001)$.

\section{DISCUSSÃO}

Nesta pesquisa foi realizada, a comparação do nível de conhecimento de escolares sobre aleitamento materno antes e depois de intervenção educacional.

Sabe-se que os escolares nem sempre são expostos à temática da amamentação no dia-a-dia, e surge a necessidade de conscientização quanto à importância dessa prática ${ }^{(12-5)}$.

Pode observar que quanto ao perfil sociodemográfico dos escolares pesquisados a maioria dos participantes era do sexo feminino $(70,8 \%)$, de cor parda $(50 \%)$, possuíam 8 anos de idade $(58,3 \%)$ e residiam na área urbana da cidade (91,7\%),

Quanto ao nível de conhecimento dos escolares sobre aleitamento materno avaliado antes da aplicação da intervenção educativa, constatou-se que os escolares pesquisados não obtinham conhecimentos sobre a prática da amamentação. Entre estes à maioria não sabiam quanto tempo um bebê deve ser amamentado exclusivamente e $(66,7 \%)$ e $75 \%$ tão pouco sabiam até quando deve receber o leite da mãe, assim como em estudo recente realizado com adolescentes brasileiros que demostrou resultados semelhantes ${ }^{(13)}$.

Ainda, metade dos entrevistados julgou como correto dar outro tipo de leite que não fosse o materno para o lactente.

Fonte: dados da pesquisa. 
E quase todos $(83,3 \%)$ achavam correto o uso de mamadeiras e chupetas por bebês, demonstrando falta de conhecimento do tema, assim como em estudo nacional ${ }^{(14)}$ em que a maioria dos adolescentes participantes da pesquisa afirmaram que forneceriam chupeta a seus futuros filhos.

No tocante a importância de se trabalhar esse tema no currículo escolar Pesquisa realizada em Coimbra, Portugal identificou que o conteúdo sobre aleitamento materno está presente nos manuais do $1^{\circ}$ ao $4^{\circ}$ ano da rede de ensino pública, porém abordado de maneira superficial. Apesar de serem constatados conteúdos favoráveis à amamentação, também foram identificadas imagens de chupeta e mamadeira. Tais ilustrações podem reforçar uma prática comumente presenciada pelas crianças e consequentemente reproduzida nas brincadeiras de infância. Esse resultado é preocupante pois o uso de chupeta é tido como fator de risco para interrupção do aleitamento materno exclusivo e o uso de bicos artificiais estarem associado à ausência de aleitamento no segundo semestre de vida da criança ${ }^{(12-15)}$.

Neste estudo, apesar do desconhecimento dos escolares sobre a duração e complementação do aleitamento materno, quase a totalidade (95,8\%) dos pesquisados acreditam que o ato de amamentar oferece ao lactente algum tipo de vantagem, mas não souberam citar nenhum exemplo. A valorização da amamentação foi o tópico em que houve os melhores escores, e o leite materno foi apontado como o melhor alimento, havendo dificuldade em apontar aspectos específicos, como duração da amamentação, diferente do demostrado em pesquisa nacional com adolescentes, onde apenas $15 \%$ dos estudantes foi capaz de citar ao menos um benefício do aleitamento materno as crianças como por exemplo aumento dos escores de inteligência ${ }^{(14)}$.

Nesta perspectiva podemos compreender que através do brincar a criança vai desde cedo construindo os seus próprios valores sobre amamentação e inicia a sua preparação para as atividades que serão desenvolvidas mais tarde na vida adulta
Nesta perspectiva

podemos

compreender que

através do brincar

a criança vai desde

cedo construindo

os seus próprios

valores sobre

amamentação

e inicia a sua

preparação

para as atividades

que serão

desenvolvidas mais

tarde na vida adulta.

(16), por isso, este estudo propôs, através de uma intervenção educativa com uso de uma história em quadrinhos e um jogo educativo, enfatizar a importância da amamentação e conhecer as experiências dos escolares sobre a amamentação de forma lúdica.
É preciso enaltecer o papel que a escola desempenha no processo de formação crítica e na construção de saberes na vida dos cidadãos, observando o nível de escolaridade e sua correlação com o nível de saúde da população estudada e de grupos populacionais específicos como crianças na fase escolar. Ademais a escola trata-se de ambiente ideal para promoção de saúde, uma vez que seu público é cativo ${ }^{(15-17)}$.

Ao comparar os escores de conhecimento sobre a temática pode-se observar que após as intervenções houve melhora significante do conhecimento, demonstrando assim que a intervenção educativa, com uso da história em quadrinhos e a amarelinha, surtiu efeito positivo no aprendizado dos escolares sobre aleitamento materno. Dessa maneira, percebe-se que a curiosidade natural de crianças associada ao uso de tecnologias educativas como veículo de informaçôes pertinentes à saúde pública, podem ser consideradas por outros autores no desenvolvimento de novas pesquisas.

Evidencia-se assim a necessidade da inserção da temática de aleitamento materno no seio familiar e no currículo escolar de forma efetiva, pois a decisão de amamentar requer um contato precoce e duradouro com a temática ${ }^{(18)}$.

Inúmeros programas de promoção do aleitamento materno são implementados no Brasil, no entanto, ainda são necessárias novas estratégias que envolvam grupos populacionais capazes de conscientizar e de serem também formadores de opinião. As crianças são consideradas grupo especial no desenvolvimento da conscientização da amamentação. Além de serem reprodutores de informações, quando adultos podem tomar decisôes positivas ao aleitamento materno e tornarem-se sujeitos sociais na luta em defesa da saúde e da vida.

\section{CONCLUSÃO}

A promoção da saúde escolar realizada por esta pesquisa mostrou-se vantajosa para que os escolares recebessem informações sobre AM e se despertassem para a necessidade de divulgação do conteúdo 


\section{artigo}

Leão, M.K.S.; Franco, M.S.; Sousa, G.B.; Nobre, R.S.; Vale, H.S.; Lima, L.H.O.

Efeitos de intervenção educativa no conhecimento de escolares sobre aleitamento materno

desde cedo e de modo progressivo. Essas ações poderão encorajar os escolares a assumirem comportamentos de saúde mais conscientes e saudáveis, favorecer o desenvolvimento de atitudes positivas a essa prática, maior apoio a mulher no ato de aleitar e, possivelmente, aumentar a intenção futura dessas crianças em amamentar e refletir no sucesso da amamentação.

Dessa forma, através dos dados mostrou-se que os escolares valorizam a amamentação, mas têm poucos conhe- cimentos e algumas percepçóes e crenças negativas com relação a essa prática. Essas informações são importantes, e devem ser levadas em consideração na elaboração de estratégias de promoção do AM entre os escolares do ensino fundamental.

\section{REFERÊNCIAS}

1. Martins FDP, Pontes CM, Javorski M, Gomes LF, Barros ACR de, Leal LP. Construção e validação de instrumento avaliativo do conhecimento de escolares sobre amamentação. Acta Paul Enferm. 2017 Set; 30(5): 466-78. DOI: http://dx.doi. org/10.1590/1982-0194201700068.

2. Victora CG, Bahl R, Barros AJD, França GV, Horton S, Krasevec J, et al. Breastfeeding. Breastfeeding in the 21st century: epidemiology, mechanisms, and lifelong effect. Lancet. 2016; 387(10017):475-90.

3. Ministério da Saúde (BR), Secretaria de Atenção à Saúde, Departamento de Ações Programáticas e Estratégicas. II Pesquisa Prevalência do Aleitamento Materno nas Capitais Brasileiras e Distrito Federal [Internet]. Brasília: Ministério da Saúde; 2009 [cited 2020 Ago 26]. Available from: http://bvsms.saude.gov. br/bvs/publicacoes/pesq uisa_prevalencia_aleitamento_materno.pdf

4. Martins FDP, Leal LP, Linhares FMP, Santos AHS, Leite GO, Pontes CM. Effect of the board game as educational technology on schoolchildren's knowledge on breastfeeding. Rev. Latino-Am. Enfermagem. 2018;26:e3049.

5. Fujimori M, Morais TC, França EL, de Toledo OR, HonórioFrança AC. The attitudes of primary school children to breastfeeding and the effect of health education lectures. J Pediatr. 2008; 84(3):224-31.

6. Corrêa AD, Rôças G, Matos LR, Alves LA. A Utilização de uma História em Quadrinhos como Estratégia de Ensino sobre o Uso Racional de Medicamentos. Revista de Educação em Ciência e Tecnologia [serial on Internet]. 2016 ago [cited 2020

ago 14];9(1):83-102, 2016. Available from: https://periodicos. ufsc.br/index.php/alexandria/article/viewFile/1982-5153.201 6v9n1p83/31792.

7. Martins FD, Leal LP, Guedes TG, Javorski M, Pontes CM. Promotion of breastfeeding on primary education: integrative review. Rev Eletr Enf. 2016; 18:e1198.

8. Nobre RS, Franco MS, Sousa GB, Leão MKS, Vale HS, Lima LHO. Conhecimento de escolares sobre aleitamento materno. Rev enferm UFPE on line [serial on Internet]. 2019 ago: [cited 2020 ago 14] 13(e)241927. Available from: https://doi. org/10.5205/1981-8963.2019.241927.

9. Nobre RS. Construção e validação de uma tecnologia educativa sobre promoção da cultura do aleitamento materno em escolares. [dissertação] Teresina; Mestrado Acadêmico em Ciências e Saúde - Universidade Federal do Piauí, 2018.
10. Beghini AB, Salimena AMO, Melo MCSC, Souza IEO. Nursing students' adhesion to gynaecological cancer: from theory to practice. Texto context enferm. [serial on Internet]2006 ago: [cited 2020 ago 14] 15(4):637-44. Available from:10.1590/S0104-07072006000400012

11. Ministério da Saúde (BR), Conselho Nacional de Saúde. Resolução $n^{\circ}$ 466, de 12 de dezembro de 2012 [Internet]. Brasília: Ministério da Saúde; 2012 [cited 2019 June 1]. Available from: http://conselho.saude.gov.br/resolucoes/2012/Res0466.pdf.

12. Galvão DM, Silva IA. Abordagem da amamentação nos primeiros anos do ensino fundamental. Rev Esc Enferm USP[serial on Internet]. 2013 ago: [cited 2020 ago 14] 47(2):477- 485. Available from: https://www.scielo.br/pdf/ reeusp/v47n2/29.pdf.

13. Pérez $M C H$, et al. Eficacia de una intervención para mejorar conocimientos y actitudes sobre lactancia materna en adolescentes. Revista Española de Salud Pública [serial on Internet] 2018 ago [cited 2020 ago 14]; 92(18):1-13. Available from: http://scielo.isciii.es/scielo.php?script=sci_arttext\&pid=S1135-57272018000100411.

14. Nakamura SS, et al. Percepção e conhecimento de meninas escolares sobre o aleitamento materno. Jornal de Pediatria [serial on Internet], 2003 ago [cited 2020 ago 14]; 79(2);181-188. Available from: http://dx.doi.org/10.1590/ S0021-75572003000200014.

15. Galvão DMPG, Silva IA. Conhecendo as vivências de amamentação da criança brasileira que frequenta o ensino fundamental [Internet]. Revista Eletrônica de Enfermagem. [serial on Internet] 2011 ago: [cited 2020 ago 14] 13(3): 377385.Available from: http://www.fen.ufg.br/revista/v13/n3/pdf/ v13n3a02.pdf

16. Galvão DMPG, Silva IA. The approach to breastfeeding in the first years of elementar school. Rev Esc Enferm USP. 2013; 47(2):477- 85.

17. Lanes KG, Copetti J, Lara S, Lannes DVC, Puntel RL, Folmer V. Estratégias de promoção da saúde do escolar a partir da abordagem de temas geradores. Experiências em Ensino de Ciências. 2014; 9(2):154-69.

18. Ho, Y. J, Mcgrath, J. M. Effectiveness of a Breastfeeding Intervention on Knowledge and Attitudes Among High School Students in Taiwan. Journal of Obstetric, Gynecologic, \& Neonatal Nursing, [serial on Internet]. 2016, [cited 2020 ago 29]; 45; 71-77. Available from: https://www.jognn.org/action/showPdf?pii=S0884-2175\%2815\%2900010-6. 